\title{
An Anti-Cancer Cordycepin Produced by Cordyceps militaris Growing on the Dead Larva of Bombyx mori Silkworm
}

\author{
Pornanong Aramwit ${ }^{1}$, Nipaporn Bang ${ }^{1}$, Juthamas Ratanavaraporn ${ }^{2}$, Titpawan Nakpheng ${ }^{3} \&$ Teerapol Srichana ${ }^{3}$ \\ ${ }^{1}$ Bioactive Resources for Innovative Clinical Applications Research Unit and Department of Pharmacy Practice, \\ Faculty of Pharmaceutical Sciences, Chulalongkorn University, Phatumwan, Bangkok, Thailand \\ ${ }^{2}$ Department of Chemical Engineering, Faculty of Engineering, Chulalongkorn University, Phatumwan, Bangkok, \\ Thailand \\ 3 Department of Pharmaceutical Technology and Drug Delivery System Excellence Center, Faculty of \\ Pharmaceutical Sciences, Prince of Songkla University, Hat Yai, Songkla, Thailand \\ Correspondence: Pornanong Aramwit, Bioactive Resources for Innovative Clinical Applications Research Unit \\ and Department of Pharmacy Practice, Faculty of Pharmaceutical Sciences, Chulalongkorn University, PhayaThai \\ Road, Phatumwan, Bangkok 10330, Thailand. Tel: 66-899-217-255. E-mail: aramwit@gmail.com
}

\author{
Received: February 13, 2014 Accepted: March 31, 2014 Online Published: May 15, 2014 \\ doi:10.5539/jas.v6n6p41 URL: http://dx.doi.org/10.5539/jas.v6n6p41
}

\begin{abstract}
In this study, we introduced the dead pupa and larva of Bombyx mori silkworms as nutrition medium for the growing of different fungi including Cordyceps militaris, Isaria tenuipes and Isaria farinose to produce Cordyceps mycelia and anti-cancer cordycepin. The anti-proliferative and anti-migratory activities of cordycepin extracted toward cancer cells were investigated. We found that the dead silk larva which contained high carbohydrate and moisture but low fat content could be a good host for the growth of Cordyceps militaris and Isaria tenuipes to produce Cordyceps. The cordycepin extracted from Cordyceps mycelia of Cordyceps militaris grown on dead silk larva showed the highest anti-proliferative potential toward human non-small cell lung cancer NCI-H460 cells with a half maximal inhibitory concentration $\left(\mathrm{IC}_{50}\right)$ of $0.7 \mu \mathrm{M}$. Furthermore, the viability of human lung adenocarcinoma epithelial A549 cell line remained $<20 \%$ while that of human airway epithelial Calu-3 cell line was $<40 \%$ after treated with the cordycepin extracted $(0.125-2 \mu \mathrm{M})$ due to the disruption of cell membrane by cordycepin. We also found that our cordycepin $(0.25-2 \mu \mathrm{M})$ could inhibit the migration of A549 cells. On the other hand, the cordycepin was not toxic to small airway epithelial cells (SAEC) of non-cancer cells. Therefore, Cordyceps militaris grown on the dead larva of B. mori silkworms was introduced as a promising source for the production of Cordyceps mycelia and anti-cancer cordycepin without toxicity to non-cancer cells.
\end{abstract}

Keywords: Cordyceps militaris, cordycepin, silk larva, cancer, anti-proliferative, anti-migratory

\section{Introduction}

Mushrooms have high value in agricultural and food industry. They are recognized as a natural source of functional herbal medicine for centuries, particularly in China, Korea and Japan (Khan et al., 2010; Ng \& Wang, 2005). Cordyceps mycelia mushroom, a genus of ascomycete fungi growing on the larva of Lepidoptera, has been used to treat conditions including respiration and pulmonary diseases; hyposexuality and hyperlipidemia; renal, liver, and cardiovascular diseases (Zhu et al., 1998). It is also used in the treatment of immune disorders and cancer (Holliday \& Cleaver, 2008; Zhu et al., 1998). Nowadays, over 400 species of Cordyceps mycelia have been described (Zhu et al., 1998). Cordyceps militaris (an entomopathogenic fungus), which is belonging to the class Ascomycetes, is one of the most important species that has been used as a crude drug and a folk tonic food (Patel \& Ingalhalli, 2013). The chemical constituents extracted from Cordyceps mycelia include cordycepin (3'-deoxyadenosine) and its derivatives, ergosterol, polysaccharides, a glycoprotein, and peptides containing $\alpha$-aminoisobutyric acid.

Cordycepin is the main active constituent which was first extracted from Cordyceps militaris (Mao et al., 2005; Masuda et al., 2006; Das et al., 2010; Masuda et al., 2011; Zhu et al., 2011; Jeong et al., 2012) and then found to be present in Cordyceps sinensis and Cordyceps kyushuensis (Li et al., 2002; Ling et al., 2009). The cordycepin (3-deoxyadenosine, $\mathrm{C}_{10} \mathrm{H}_{13} \mathrm{~N}_{5} \mathrm{O}_{3}$ ), as a nucleoside analogue, is a nucleic acid antibiotic that inhibits canceration 
of cells, contributing to the normalization of cancer cells as one of constituents of gene DNA (Cunningham et al., 1951). Furthermore, cordycepin can be incorporated into RNA molecules causing premature termination of RNA dyssynthesis, contributing to its anti-cancer activity (Paterson, 2008). In addition, various pharmacological actions of cordycepin such as anti-inflammation, anti-bacterial, and anti-tumor activities have been reported (Ahn et al., 2000; Jeong et al., 2010; Khan et al., 2010; Lee et al., 2011). Jeong et al. (2010) demonstrated the anti-inflammatory effect of cordycepin on the production of inflammatory mediators in lipopolysaccharide (LPS)-stimulated murine BV2 microglia. Its inhibitory effect is associated with the suppression of the NF- $\mathrm{kB}$, Akt, and MAPK signaling pathways. Lee et al. (2011) reported that cordycepin showed anti-proliferative and apoptotic effects on carcinoma cell lines in vitro in a dose dependent manner. However, there is a great variation in the activity of cordycepin extracted from different sources of Cordyceps mycelia and it is difficult to control the natural Cordyceps mycelia sources. Due to this reason, Cordyceps mycelia grown on artificial diet should have more consistent quality. In this study, the dead pupa and larva of B. mori silkworm were introduced as nutrition medium for the growing of different fungi including Cordyceps militaris (C. militaris), Isaria tenuipes (I. tenuipes) and Isaria farinose (I. farinose) to produce Cordyceps mycelia.

Dead insects have been used as host medium for the growth of fungi (Li et al., 2002). Various Cordyceps mycelia fungi growing on the dead insects have been studied (Paterson, 2008). Silkworm has been an economically important insect of silk agriculture and food industry in Asian countries for centuries. Large numbers of silkworms were breed for the production of raw silk, thereafter the dead silkworms were the waste product from the process. To increase the value of dead silkworms, they were introduced as host which is considered as artificial diet food for the production of Cordyceps mycelia with more consistent quality. The dead pupa and larva of B. mori silkworms were studied for their proximate composition as growth media. The Cordyceps mycelia were produced by growing fungi including C. militaris, I. tenuipes or I. farinose on the dead larva of silkworms. The cordycepin was extracted from various Cordyceps mycelia at different extraction conditions. Yield of cordycepin extracted was analyzed using High Performance Liquid Chromatography (HPLC) technique. The anti-proliferative and anti-migratory activities of cordycepin extracted on various cancer cells including human non-small cell lung cancer NCI-H460 cells, human lung adenocarcinoma epithelial cell line (A549 cells), and human airway epithelial cell line (Calu-3 cells) and its reaction on cell were investigated. On the other hand, cytotoxic test of cordycepin extracted on non-cancer cells, Small Airway Epithelial Cells (SAEC), was performed. In addition, an anti-tyrosinase activity of the cordycepin extracted was assessed.

\section{Materials and Methods}

\subsection{Materials}

The third-, fifth-instars pupae and larvae of B. mori strain Chul 3/2 (green-shell cocoons) were kindly supplied by Chul Thai Silk Co., Ltd. (Petchaboon province, Thailand). The spores of C. militaris (NBRC 100741), I. tenuipes (NBRC 100738), and I. farinose (NBRC 100648) were purchased from National Institute of Technology and Evaluation (Tokyo, Japan). Commercial Cordyceps mycelia was purchased from traditional Chinese medicine store in Bangkok, Thailand which was claimed as natural Cordyceps mycelia. Other chemicals were analytical grade and used without further purification.

\subsection{Analysis of Proximate Composition in Dead Pupa and Larva of Silkworms}

Protein content in the dead body of silk pupa and larva was determined according to the principle of Kjeldahl method (Lynch \& Barbano, 1999) on a mechanized and automated Kjeltec instrument (Foss). Sample (1 g) was digested with $15 \mathrm{~mL}$ of concentrated sulphuric acid using electrically heated aluminum block digester. The digested sample was diluted and then adjusted to alkaline with $50 \mathrm{~mL}$ of $40 \mathrm{wt} \%$ sodium hydroxide, followed by a rapid steam distillation of ammonia from the sample into $25 \mathrm{~mL}$ of $4 \mathrm{vol} \%$ boric acid for a manual titration with $0.2 \mathrm{~N}$ of hydrochloric acid. A conversion factor of 6.25 was used to convert the measured nitrogen content to protein content.

Carbohydrate content of sample was determined by the Clegg-anthrone method (Nollet, 2004). Sample (1 g) was digested with $13 \mathrm{~mL}$ of $52 \mathrm{vol} \%$ perchloric acid to hydrolyze disaccharides, trisaccharides and higher oligomers to their reducing sugar components and then reacted with anthrone reagent under acidic condition to produce a blue/green color. Anthrone reagent was prepared by dissolving $0.1 \mathrm{wt} \%$ anthrone in diluted sulphuric acid (a ratio of sulphuric acid:water $=2.3: 1 \mathrm{vol} / \mathrm{vol})$. An aliquot $(1 \mathrm{~mL})$ of appropriately diluted hydrolysate was mixed with $5 \mathrm{~mL}$ of anthrone reagent. After incubated in boiling water for $12 \mathrm{~min}$ and cooled down, the absorbance of the reaction mixture was measured at $630 \mathrm{~nm}$. A standard curve was prepared from glucose $(0-100 \mathrm{mg} / \mathrm{L})$.

Total fat of sample was determined by the semi-continuous solvent extraction method. The sample $(10 \mathrm{~g})$ was extracted with $180 \mathrm{~mL}$ of petroleum ether on a Soxhlet apparatus for $10 \mathrm{~h}$. Petroleum ether was removed by 
evaporation and the residue of lipid was weight (Tee et al., 1996).

Moisture content of sample was determined using the direct drying method. Homogenized sample (10 g) was dried overnight in an air-oven at $105^{\circ} \mathrm{C}$ until constant weight of the sample was obtained. The difference between initial weight and final constant weight after drying was taken to be moisture lost and moisture content of sample (Tee et al., 1996).

The amount of crude fiber was estimated using acid washing method. Milled powder of samples $(1 \mathrm{~g})$ was added into a glass flask containing $100 \mathrm{~mL}$ of washing acid (2 vol\% Cetyltrimethylammonium Bromide (CTAB) in $1 \mathrm{~N}$ sulphuric acid) and boiled for $1 \mathrm{~h}$ with shaking. After filtration on a Buchner, the residue was dried at $105^{\circ} \mathrm{C}$ until constant weight was reached and weighed as crude fiber content (Amir et al., 2007).

Ash content of sample was determined using the dry ashing method. Sample $(10 \mathrm{~g})$ was incinerated in a cold muffle furnace at $550^{\circ} \mathrm{C}$ until whitish/grayish ash was obtained. Organic component was burned off and the inorganic material remained was cooled and weighted as ash content (Tee et al., 1996). All samples were analyzed in triplicate.

\subsection{Culture of Fungi for the Production of Cordyceps Mycelia}

C. militaris, I. tenuipes and I. farinose were cultured in Potato Dextrose Agar (PDA) medium (Lot No. 09240, Criterion, Hardy Diagnostics) for 20 days and then subcultured to expand the microorganisms for further experiments. The microorganisms were then cultured in slant medium consisting of silk pupa, soy sauce, trehalose, magnesium sulfate and agar for another 2-3 weeks to grow the spores. The spores were dissolved in 1 vol\% tween 80 to obtain the concentration of 108 spores $/ \mathrm{mL}$. The growth medium for the production of Cordyceps mycelia was prepared from artificial diet composed of silk larva, soy sauce, trehalose dissolved in deionized water. The spores were added into the growth medium and cultured for 60 days to obtain Cordyceps mycelia.

\subsection{Extraction of Cordycepin From Cordyceps Mycelia}

The Cordyceps mycelia from various sources $(5 \mathrm{~g})$ was dissolved in deionized water at $25^{\circ} \mathrm{C}$ or $95^{\circ} \mathrm{C}$ with continuous shaking for $1 \mathrm{~h}$. Then, the sample solutions were filtrated through a $0.22 \mu \mathrm{m}$ membrane. The filtrate was analyzed for cordycepin content using High Performance Liquid Chromatography (HPLC) technique. An HPLC system consisted of a P680 liquid chromatographic pump (Dionex, Sunnyvale, CA, USA), a ASI-100 automated sample injector with a $20 \mu \mathrm{L}$ loop (Dionex, Sunnyvale, CA, USA), an UVD170U detector (Dionex, Sunnyvale, CA, USA). A VertisepTM AQS C18 HPLC column ( 250 x 4.6 mm i.d., $5 \mu$ m particle size, Vertical Chromatography Co., Ltd, Bangkok, Thailand) was used for chromatographic separation at ambient temperature. The method of HPLC analysis for cordycepin was slightly modified from Ikeda et al. (2008). The mobile phase was a mixture of acetonitrile : water $(5: 95 \mathrm{vol} / \mathrm{vol})$ and the flow rate was set at $1.0 \mathrm{~mL} / \mathrm{min}$. The UV detection was operated at $260 \mathrm{~nm}$. Three analytical samples were prepared from each Cordyceps mycelia sample, which were determined in triplicate.

\subsection{Cell Culture}

Human non-small cell lung cancer NCI-H460 cells (ATCC HTB-177, Manassas, VA, USA) were cultured in Roswell Park Memorial Institute (RPMI) 1640 medium (Invitrogen, Carlsbad, CA) supplemented with 5 vol\% fetal bovine serum (FBS), $2 \mathrm{mM}$ L-glutamine, and $100 \mathrm{U} / \mathrm{mL}$ penicillin-streptomycin. Human lung adenocarcinoma epithelial cell line, A549 cells (ATCC CCL-185, Rockville, MD, USA) were cultured in Ham's F-12K (Kaighn's) medium supplemented with $10 \mathrm{vol} \% \mathrm{FBS}$ and $100 \mathrm{U} / \mathrm{mL}$ penicillin-streptomycin. Human airway epithelial cell line, Calu-3 cells (ATCC HTB-55, Rockville, MD, USA) was cultured in Modified Eagles Medium (MEM) supplemented with $10 \mathrm{vol} \% \mathrm{FBS}$ and $50 \mathrm{U} / \mathrm{mL}$ penicillin-streptomycin. Non-cancer cells, small airway epithelial cells (SAEC, ATCC PCS-301-010, Manassas, VA, USA), were maintained in small airway epithelial cells basal medium (SABM) supplemented with growth factors supplied in the SAGM SingleQuot kit (Lonza $^{\mathrm{TM}}$, Walkersville, Inc., USA). All cells were maintained at $37^{\circ} \mathrm{C}$ in a $5 \% \mathrm{CO}_{2}$ and $95 \%$ humidity incubator and the media were changed every 2-3 days. When reached $80 \%$ confluency, the cells were subcultured and expanded for the experiments.

\subsection{Cytotoxic Test of Cells Cultured With Cordycepin Extracted}

The cells $\left(1 \times 10^{5}\right.$ cells $\left./ \mathrm{mL}, 100 \mu \mathrm{L}\right)$ were seeded on each well of a 96 -well plate and cultured at $37^{\circ} \mathrm{C}$ in a $5 \%$ $\mathrm{CO}_{2}$ and $95 \%$ humidity incubator overnight to allow cells to adhere. On the following day, the culture medium was replaced with fresh media $(100 \mu \mathrm{L})$ and the medium containing different concentrations of cordycepin extracted $(0.125,0.25,0.5,1$, and $2 \mu \mathrm{M})$ was added. The cells were then cultured for further $24 \mathrm{~h}$. The viability of cells was determined by 3-(4,5-dimethylthiazolyl-2-yl)-2,5-diphenyl-tetrazolium bromide (MTT) assay 
(Mosmann, 1983; Edmondson et al., 1988). Briefly, the culture medium was removed and MTT solution (1.25 $\mathrm{mg} / \mathrm{mL}, 200 \mu \mathrm{L}$ ) was added into each well, followed by incubation at $37^{\circ} \mathrm{C}$ for $4 \mathrm{~h}$. After incubation, the MTT solution was aspirated and the formazan product was solubilized with DMSO $(200 \mu \mathrm{L})$. The absorbance of solution was measured at $570 \mathrm{~nm}$ using a multi-detection microplate reader (Biohit BP 800, Helsinki, Finland). The numbers of viable cells in the treated well were compared to those in the untreated well and calculated as percentage of cell viability.

\subsection{Observation of Cell Morphology Using Transmission Electron Microscopy (TEM)}

A549 cells were seeded at a concentration of $10^{6}$ cells $/ \mathrm{mL}$ into the flasks and incubated at $37^{\circ} \mathrm{C}$ in a $5 \% \mathrm{CO}_{2}$ and $95 \%$ humidity incubator for 3 days to prepare cell monolayer. After medium changing, the cordycepin extracted was added into the fresh medium at $0.125 \mu \mathrm{M}$ and incubated with cell monolayer for $24 \mathrm{~h}$. Cells cultured without the addition of cordycepin extracted were served as a control. Then, cells were harvested using $0.25 \%$ trypsin-EDTA and centrifuged at $130 \mathrm{~g}$ for $5 \mathrm{~min}$. The cell pellets were prepared for TEM observation by fixing with $2.5 \mathrm{vol} \%$ glutaraldehyde at $4^{\circ} \mathrm{C}$ for $4 \mathrm{~h}$. After that, cells were fixed with $1 \mathrm{vol} \%$ osmium tetroxide for $1 \mathrm{~h}$ and dehydrated with ethyl alcohol. The cells were then embedded in epoxy resin and mounted on 300 mesh copper grid, stained with uranyl acetate and lead citrate, and then observed on TEM (JEM-2010 at 200kV; JEOL, Japan).

\subsection{Migration Assay}

In vitro migration assay was performed to evaluate the anti-migratory activity of cordycepin extracted toward human lung A549 cell line. The migration assay was performed following a modified Boyden's chamber assay using 24-well transwell culture plates with $8 \mu \mathrm{m}$-pore size-polycarbonate filter (Corning/Fisher Scientific, Schwerte, Germany), as described previously (Dai et al., 2011). Briefly, A549 cells were seeded in the upper chamber $\left(5 \times 10^{4}\right.$ cells/well in $\left.100 \mu \mathrm{L}\right)$. The same media containing cordycepin extracted from Cordyceps mycelia of $C$. militaris grown on dead silk larva $(0.125-2 \mu \mathrm{M})$ was added into the lower chamber. The media without cordycepin was used as a control. Cells were incubated at $37^{\circ} \mathrm{C}, 5 \% \mathrm{CO}_{2}$ for $16 \mathrm{~h}$, then the migration of cells was evaluated. The migrated cells was fixed with $4 \%$ paraformaldehyde for $30 \mathrm{~min}$, washed with PBS and stained with trypan blue. The migrated cells were counted by using light microscope at high magnification field (20X).

\subsection{Anti-Tyrosinase Assay}

The assay was performed following the method described previously with minor modifications (Masamoto et al., 2003). Tyrosinase (1,000 units/mL, Sigma, St Louis, MO, USA) from a mushroom solution was prepared at a concentration of 100 units $/ \mathrm{mL}$ in $0.2 \mathrm{M}$ phosphate buffer solution ( $\mathrm{pH}$ 6.5). Tyrosinase mushroom solution (150 $\mu \mathrm{L})$ and phosphate buffer solution at $\mathrm{pH} 6.5(300 \mu \mathrm{L})$ were mixed with or without the cordycepin extracted $(0.8$ $\mathrm{mg}$ ). The mixture was then pre-incubated at $25^{\circ} \mathrm{C}$ for 5 min before adding $300 \mu \mathrm{L}$ of $1.25 \mathrm{mM}$ dopa (3,4-dihydroxyphenylalanine) solution. Then, the absorbance of reacted solution was measured at $475 \mathrm{~nm}$. The percentage of inhibition of tyrosinase activity was calculated as

$$
\text { Inhibition }(\%)=[(\mathrm{A}-\mathrm{B}) / \mathrm{A}] \times 100
$$

where $\mathrm{A}$ and $\mathrm{B}$ represent the difference in the absorbance of the control and test samples, respectively, between incubation times of 0.5 and $1.0 \mathrm{~min}$.

\subsection{Statistical Analysis}

All the results were statistically analyzed by the unpaired student's $t$ test and $p<0.05$ was considered to be statistically significant. Data were expressed as the mean \pm the standard deviation.

\section{Results}

\subsection{Proximate Composition of the Dead Silkworms}

The proximate composition of the dead silk pupa and larva of B. mori silkworm is presented in Table 1. Dead silk pupa contained high fat $(\sim 26.43 \mathrm{~g} / 100 \mathrm{~g})$ but low carbohydrate $(\sim 5.51 \mathrm{~g} / 100 \mathrm{~g})$ and moisture $(\sim 7.48 \mathrm{~g} / 100 \mathrm{~g})$. On the other hand, dead silk larva contained high carbohydrate $(\sim 13.65 \mathrm{~g} / 100 \mathrm{~g})$ and moisture $(\sim 12.5 \mathrm{~g} / 100 \mathrm{~g})$ but low fat $(8.51 \mathrm{~g} / 100 \mathrm{~g})$. The amounts of protein and crude fiber in the dead silk pupa and larva were not different. The dead pupa had higher energy than the dead larva. 
Table 1. Proximate composition in dead body of pupa and larva of B. mori silkworms

\begin{tabular}{|c|c|c|c|c|c|c|c|}
\hline \multirow{2}{*}{ Silkworm } & \multicolumn{6}{|c|}{ Proximate composition (g/100 g silkworm, wet basis) } & \multirow{2}{*}{ - Energy (kcal/100 g) } \\
\hline & Protein & Carbohydrate & Fat & Moisture & Crude fiber & Ash & \\
\hline Pupa & $54.9 \pm 0.4$ & $5.5 \pm 0.1$ & $26.4 \pm 0.5$ & $7.5 \pm 0.1$ & $4.1 \pm 0.1$ & $5.6 \pm 0.1$ & 480.2 \\
\hline Larva & $55.9 \pm 0.1$ & $13.7 \pm 0.1$ & $8.5 \pm 0.1$ & $12.5 \pm 0.1$ & $5.6 \pm 0.1$ & $9.4 \pm 0.2$ & 337.9 \\
\hline
\end{tabular}

\subsection{Growing of I. Tenuipes on the Dead Silk Pupa and Larva}

We found that only the dead silk larva could be a good nutrient host for the growth of I. tenuipes (Figure 1) while the dead pupa could not (unpublished data). For the further experiments of this study, only the dead silk larva was then used as a host medium for the growth of different Cordyceps mycelia fungi, including C. militaris, I. tenuipes and I. farinose.

\section{Cordyceps mycelia of $I$. tenuipes grown on the silk larva}
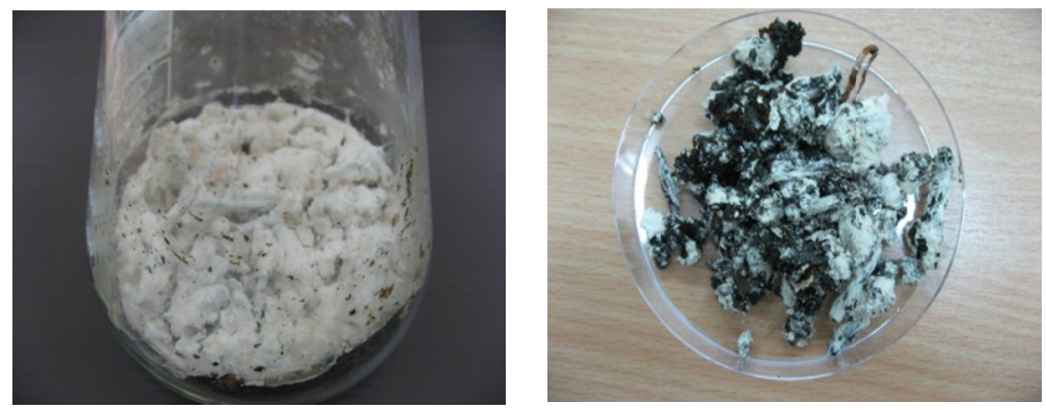

Stroma of $I$. tenuipes grown on the silk larva
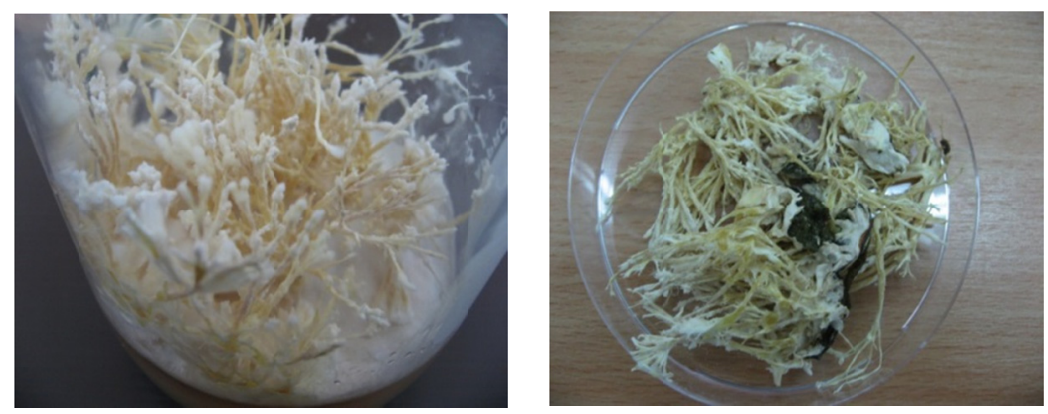

Figure 1. Macroscopic images of Cordyceps mycelia and stroma of I. tenuipes grown on dead body of silk larva

\subsection{Growing of C. Militaris, I. Tenuipes, and I. Farinose on the Dead Silk Larva}

After cultured in PDA medium for 20 days and in slant medium for further 14 days, the Cordyceps mycelia of $C$. militaris, I. tenuipes, and I. farinose were formed. After cultured on the dead silk larva, only C. militaris and I. tenuipes could grow along the culture period to produce the Cordyceps mycelia while the I. farinose could not.

\subsection{Yield of the Cordycepin Extracted from Cordyceps mycelia}

By extraction with water, the highest yield of cordycepin $(4.29 \mathrm{mg} / \mathrm{g}$-mycelia) was obtained from the Cordyceps mycelia of $C$. militaris grown on the dead silk larva extracted at $95^{\circ} \mathrm{C}$ (Table 2). The values were significantly higher than those of commercial Cordyceps mycelia (1.53-2.03 mg/g-mycelia). On the other hand, the lowest yield of cordycepin was obtained when extracted from the Cordyceps mycelia of I. tenuipes grown on the dead 
silk larva $\left(0.0058-0.0167 \mathrm{mg} / \mathrm{g}\right.$-mycelia). In addition, the water extraction temperature at $95^{\circ} \mathrm{C}$ provided the higher yield of cordycepin than the extraction at $25^{\circ} \mathrm{C}$. The purity of cordycepin extracted was confirmed by calculating area under the peak of cordycepin compared with the area under the peaks of other impurities. The results indicated that the extract contains approximately $84.12 \pm 5.67 \%$ of cordycepin.

Table 2. Yield of cordycepin extracted from different sources of Cordyceps mycelia at different extraction temperatures

\begin{tabular}{lcc}
\hline Source of Cordyceps mycelia & $\begin{array}{c}\text { Extraction temperature } \\
\left({ }^{\circ} \mathbf{C}\right)\end{array}$ & $\begin{array}{c}\text { Yield of codycepin extracted } \\
\text { (mg/g-mycelia) }\end{array}$ \\
\hline Cordyceps mycelia of C. militaris & 25 & $4.1917 \pm 0.0280^{*}$ \\
grown on dead silk larva & 95 & $4.2933 \pm 0.0420^{*}$ \\
\hline Cordyceps mycelia of I. tenuipes & 25 & $0.0058 \pm 0.0002 *$ \\
grown on dead silk larva & 95 & $0.0167 \pm 0.0004 *$ \\
\hline Commercial Cordyceps mycelia & 25 & $1.5330 \pm 0.0031$ \\
& 95 & $2.0310 \pm 0.0016$ \\
\hline
\end{tabular}

$* p<0.05$, significant against the values of commercial Cordyceps mycelia at the corresponding extraction temperature.

\subsection{Anti-Proliferative Action of the Cordycepin Toward NCI-H460 Cells}

The viability of human non-small cell lung cancer NCI-H460 cells when cultured in the presence of various concentrations of cordycepin is shown in Figure 2. The percentages of cell viability were decreased when the concentration of cordycepin increased. At any cordycepin concentrations, the cell treated with the cordycepin extracted from Cordyceps mycelia of C. militaris grown on dead silk larva showed lower percentage of viability than those treated with the cordycepin extracted from Cordyceps mycelia of I. tenuipes and commercial Cordyceps mycelia. With the cordycepin extracted from Cordyceps mycelia of C. militaris, the viability of cells remained $20 \%$ after treated at $10 \mu \mathrm{M}$ and its half maximal inhibitory concentration $\left(\mathrm{IC}_{50}\right)$ was $0.7 \mu \mathrm{M}$.

\subsection{Anti-Proliferative Action of the Cordycepin Extracted Toward A549, Calu-3, and SAEC Cells}

The viability percentage of human lung adenocarcinoma epithelial cell line, A549 cells, human airway epithelial cell line, Calu-3 cells, and SAEC after treated with different concentrations of the cordycepin extracted from Cordyceps mycelia of C. militaris grown on dead silk larva is shown in Figure 3. The two types of cancer cells, A549 and Calu-3 cells, showed low percentage of viability when treated with this cordycepin. At any cordycepin concentrations, the viability percentage of A549 cells remained $<20 \%$ while that of Calu- 3 cells was $<40 \%$. The membrane of A549 cells, as a representative of cancer cell, exposed to this cordycepin was disrupted while the fluid inside the cells was released (head arrow), resulting in cell dead (Figure 4). In contrast, a large nucleus as well as the presence of vacuole with normal cytoplasm appearance was observed in the control cells. On the other hand, the viability of SAEC, as a representative of non-cancer cells, treated with any concentrations of cordycepin were $>90 \%$ (Figure 3 ). 

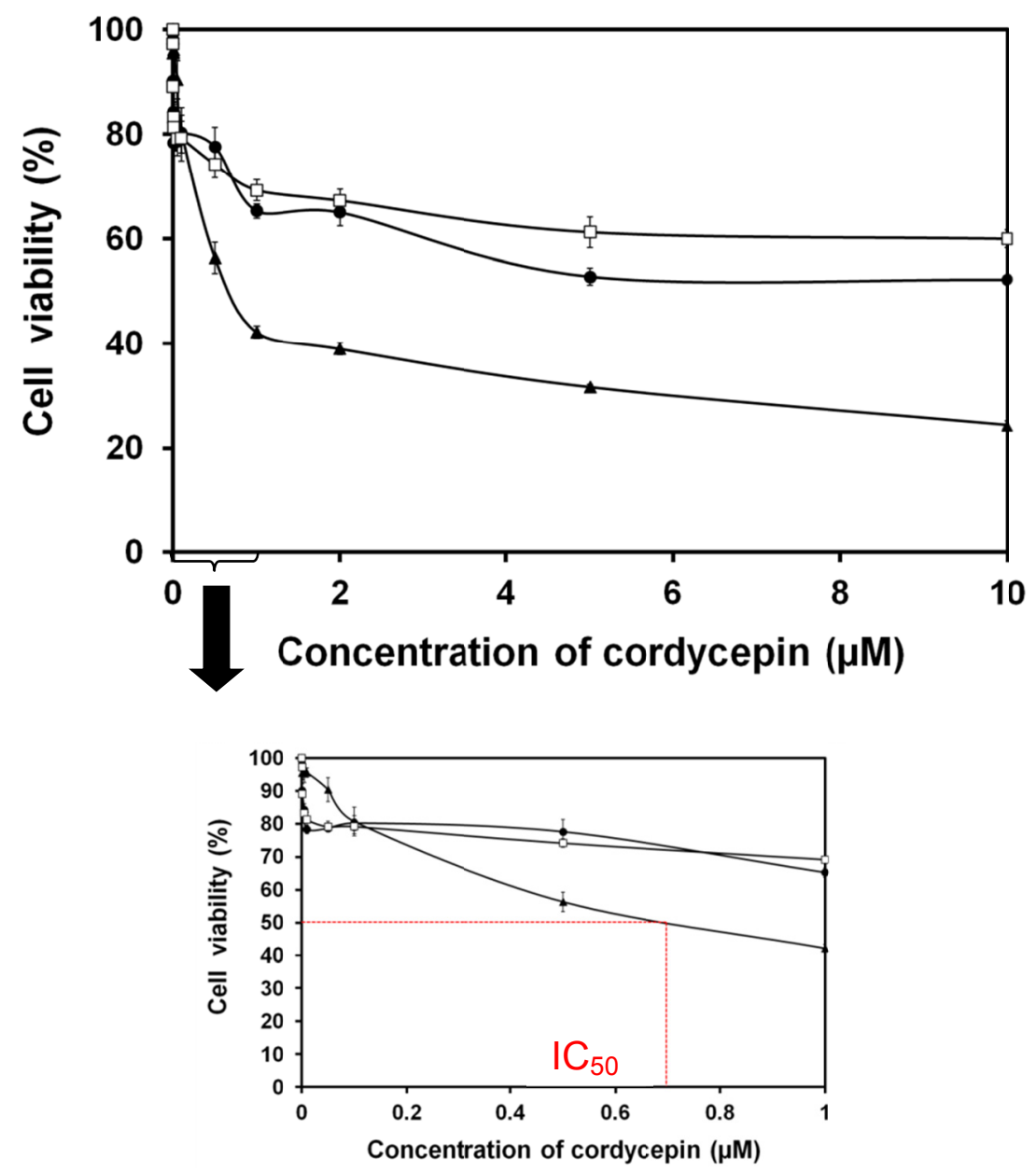

Figure 2. Viability percentage of human non-small cell lung cancer NCI-H460 cells after treated with cordycepin extracted for 24 h. Cordycepin extracted from Cordyceps mycelia of C. militaris $(\boldsymbol{\Delta})$ and I. tenuipes $(\bullet)$ grown on dead silk larva for 60 days, and commercial Cordyceps mycelia ( $\square)$

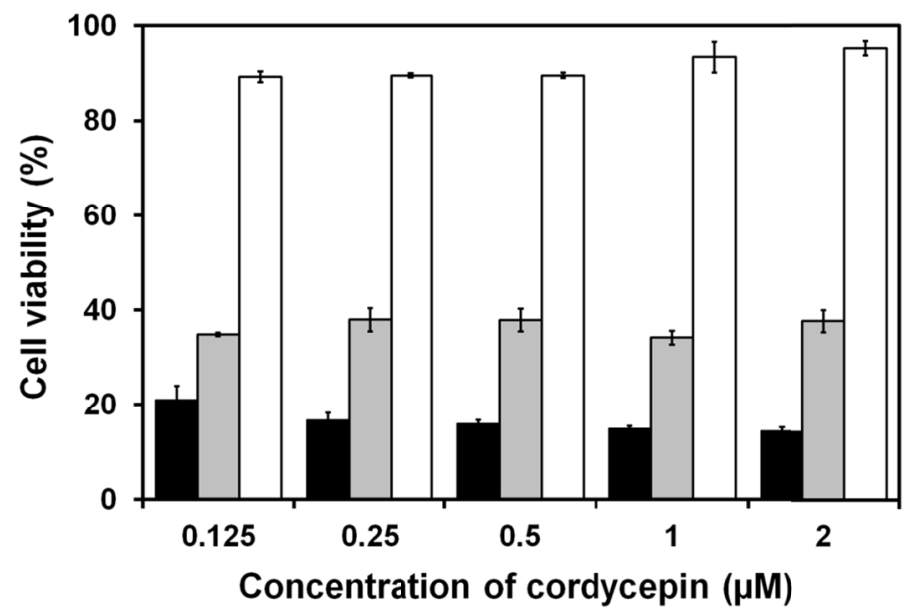

Figure 3. Viability percentage of human lung adenocarcinoma epithelial cell line, A549 cells (๘), human airway epithelial cell line, Calu-3 cells ( $\square$ ), and small airway epithelial cells (SAEC) ( $\square$ ) after treated with different concentrations of the cordycepin extracted for $24 \mathrm{~h}$. The cordycepin was extracted from Cordyceps mycelia of $C$. militaris grown on dead silk larva for 60 days 

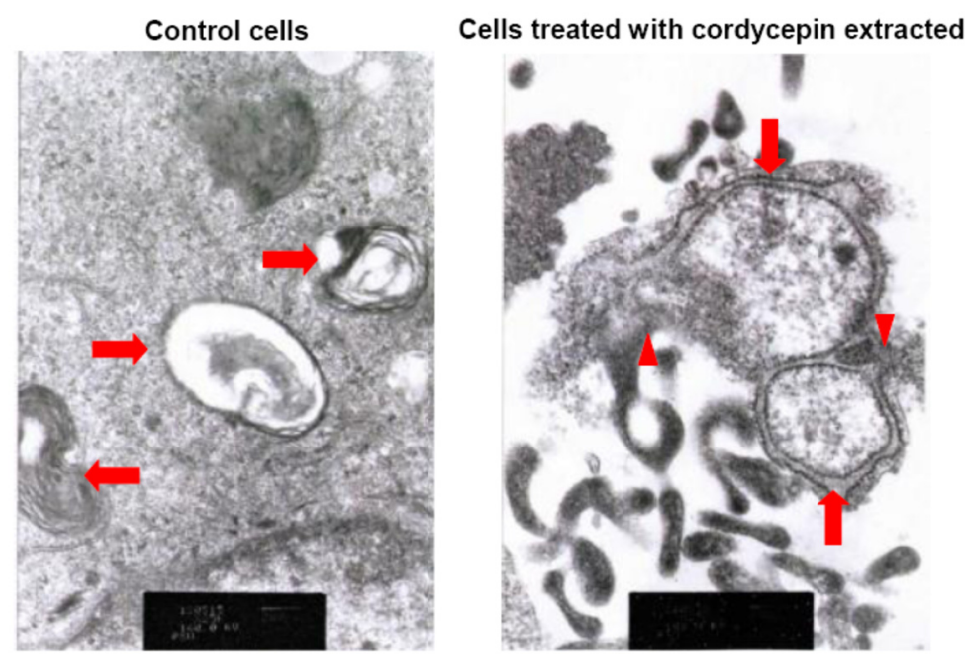

Figure 4. Morphology of human lung adenocarcinoma epithelial cell line, A549 cells, after treated with 0.125 $\mu \mathrm{M}$ cordycepin extracted for $24 \mathrm{~h}$, observed on TEM. The cordycepin was extracted from Cordyceps mycelia of C. militaris grown on the dead silk larva for 60 days and control cells were cultured without the addition of the cordycepin extracted (arrow: cells, head arrow: disrupted cell membrane)

\subsection{Anti-Migratory Effect of the Cordycepin Toward A549 Cells}

The number of A549 cells migrated into the lower chamber of 24-well transwell culture plates filled with media containing various concentrations of the cordycepin extracted from Cordyceps mycelia of C. militaris grown on dead silk larva is shown in Figure 5. It was found that the cells could migrate into the lower chamber filled with control media without cordycepin as well as the media containing low concentration of cordycepin $(0.125 \mu \mathrm{M})$. On the other hand, cells were not found in the lower chamber filled with $0.25-2 \mu \mathrm{M}$ cordycepin.

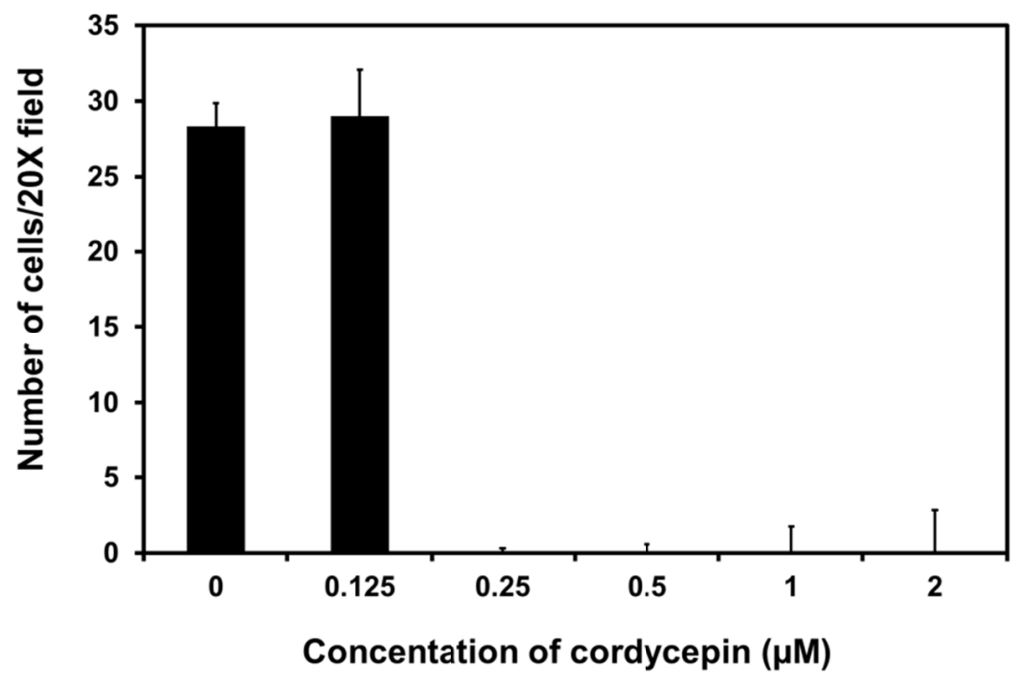

Figure 5. Number of A549 cells migrated into the lower chamber of 24-well transwell culture plates filled with media containing various concentrations of cordycepin extracted from Cordyceps mycelia of C. militaris grown on dead silk larva $(0-2 \mu \mathrm{M})$

\subsection{Anti-Tyrosinase Activity of the Cordycepin Extracted}

Figure 6 shows the anti-tyrosinase activity of the cordycepin extracted from various Cordyceps mycelia sources. The highest anti-tyrosinase activity was seen for the cordycepin extracted from Cordyceps mycelia of C. militaris 
grown. The anti-tyrosinase activities of cordycepin extracted from Cordyceps mycelia of both C. militaris and I. tenuipes were significantly higher than that of the commercial Cordyceps mycelia.

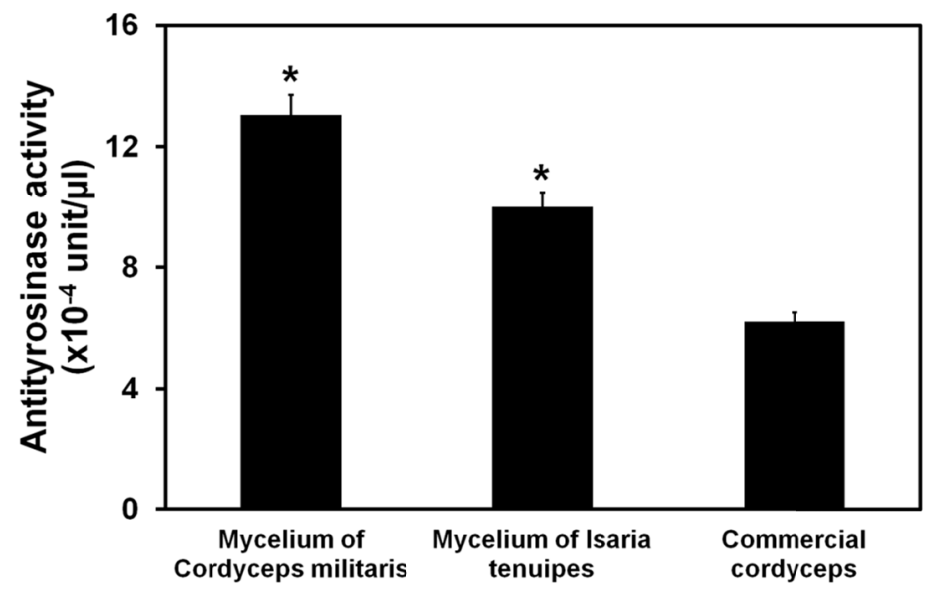

Figure 6. Antityrosinase activity of the cordycepin extracted from Cordyceps mycelia of C. militaris and I. tenuipe grown on the dead silk larva for 60 days, and commercial Cordyceps mycelia. ${ }^{*} p<0.05$, significant against the values of commercial Cordyceps mycelia

\section{Discussion}

Cordycepin which is a pure compound extracted from Cordyceps mycelia shows various biological activities such as anti-inflammation, anti-bacterial, anti-tumor, and anti-cancer (Ahn et al., 2000; Jeong et al., 2010; Lee et al., 2011). In this study, the anti-proliferative and anti-migratory activities of the cordycepin extracted from different sources of Cordyceps mycelia toward cancer cells were investigated. Dead pupa and larva of $B$. mori silkworm were selected as the insect host for the growth of Cordyceps mycelia fungi. We here reported the proximate composition of the dead silk pupa and larva (Table 1). The main differences in nutrients between the dead pupa and larva were carbohydrate, fat, and moisture. The dead silk larva contained higher carbohydrate and moisture, but lower fat than the dead pupa. We found that only the dead silk larva could be a good nutrient host for the growth $I$. tenuipes (Figure 1) while the dead pupa could not. Then, carbohydrate and moisture components would be necessary for the growth of Cordyceps mycelia fungi. In contrast, high fat composed in the dead pupa might not be suitable for the growth of Cordyceps mycelia fungi. Carbohydrate was found to be an important carbon source for the cordycepin production by submerged cultivation of $C$. militaris (Das et al., 2010; Mao et al., 2005). Mao et al. (2005) reported that lactose, sucrose, glucose, fructose, galactose, maltose, xylose, and glucose were the most favorable to cordycepin production.

Only $C$. militaris and $I$. tenuipes could grow on the dead silk larva to produce the Cordyceps mycelia. This indicated that $C$. militaris and I. tenuipes fungi could be the sources of Cordyceps mycelia production while I. farinose was not. It was previously demonstrated that a surface liquid culture of $C$. militaris could produce high yield of Cordyceps mycelia and cordycepin (Masuda et al., 2006, 2011). Masuda et al. (2006) reported that about $98 \%$ of the cordycepin synthesized by $C$. militaris was secreted into the culture medium, while other nucleic acid-related compounds except for cordycepin were only slightly observed in the medium.

Various extraction methods have been developed to extract cordycepin from Cordyceps mycelia including ultrasound- or microwave-assisted extraction, pressurized extraction, soxhlet extraction, reflux extraction, column chromatographic extraction and supercritical fluid extraction (Ling et al., 2009; Ni et al., 2009). However, the extraction with water is the simplest method which could also provide high yield of cordycepin (Wu et al., 2007; Yoshikawa et al., 2004). By the extraction with water, the highest yield of cordycepin was obtained from the Cordyceps mycelia of C. militaris grown on dead silk larva (Table 2). This indicated that C. militaris and dead silk larva would be a potential source of Cordyceps mycelia and cordycepin production. In addition, we proved that the higher extraction temperature provided the higher yield of cordycepin (Table 2). This might be due to the increased solubility of cordycepin at higher temperature. 
The anti-proliferative activity of the cordycepin extracted was elucidated (Figure 2-3). The $\mathrm{IC}_{50}$ value of cordycepin extracted from the Cordyceps mycelia of C. militaris grown on dead silk larva toward NCI-H460 cells $(0.7 \mu \mathrm{M})$ was remarkably lower than the $\mathrm{IC}_{50}$ value of cisplatin which is a potent anti-cancer drug $(80 \mu \mathrm{M})$, as reported previously (Zhang et al., 2004). Furthermore, we proved that the cordycepin extracted killed the A549 cancer cells by the disruption of cell membrane (Figure 4). The anti-proliferative activity of cordycepin on cancer cells has been widely reported (Khan et al., 2010; Kim et al., 2006; Lee et al., 2009; Wu et al., 2007; Yoshikawa et al., 2008). It was demonstrated that cordycepin inhibited the proliferation of B16-BL6 cells by stimulating adenosine A3 receptors followed by the Wnt signaling pathway, including Glycogen Synthase Kinase (GSK)-3 beta activation and cyclin D1 inhibition (Yoshikawa et al., 2008). Cordycepin markedly inhibited the phosphorylation of Akt and p38 in dose-dependent manners in LPS-activated macrophage and suppressed Tumor Necrosis Factor (TNF)-alpha expression, Ikappa B alpha phosphorylation and translocation of Nuclear Factor-kappa B (NF-KB) (Kim et al., 2006). Another molecular mechanism for the anti-cancer effects of cordycepin in two different bladder cancer cell lines, 5637 and T-24 cells was found to be related to an up-regulation of p21WAF1 expression, independent of the p53 signaling pathway (Lee et al., 2009).

We here proposed another possible mechanism, antityrosinase activity, to explain the anti-proliferative activity of cordycepin toward cancer cells. Tyrosinases are copper-containing enzymes that catalyse the ortho-hydroxylation of monophenols to catechols and their subsequent oxidation to ortho-quinones (Schurink et al., 2007). Tyrosinases are known to play roles in cancer and neurodegenerative diseases such as parkinson's disease (Aramwit et al., 2010; Cavalieri et al., 2002). Therefore, the highest antityrosinase activity of the cordycepin extracted from the Cordyceps mycelia of C. militaris grown on dead silk larva (Figure 6) possibly contributed to its highest anti-proliferative activity on cancer cells (Figure 2).

The inhibition of migration/invasion of the cordycepin toward human lung cancer cells was confirmed (Figure 5), particularly at high cordycepin concentration $(0.25-2 \mu \mathrm{M})$. This was corresponded to the results reported elsewhere (Jeong et al., 2012; Lee et al., 2010). Lee et al. (2010) found that cordycepin could suppress TNF- $\alpha$-induced invasion, migration and matrix metalloproteinase- 9 expression in human bladder cancer cells. Jeong et al. (2012) reported that cordycepin inhibited the migration and invasion of LNCaP human prostate carcinoma cells by down-regulating the activity of tight junctions and matrix metalloproteinase, possibly in association with suppression of Akt activation.

On the other hand, we proved that the cordycepin extracted was not toxic to non-cancer cells like SAEC (Figure 3). In summary, the dead body of silk larva which contained high carbohydrate and moisture but low fat could be a good host for the growth of $C$. militaris to produce Cordyceps. The cordycepin extracted from Cordyceps mycelia of C. militaris grown on dead silk larva by water extraction at $95^{\circ} \mathrm{C}$ showed the highest yield and highest anti-proliferative activity on cancer cells without toxicity to non-cancer cells. Therefore, the C. militaris and the dead body of silk larva as artificial medium were introduced as promising sources for the production of Cordyceps mycelia and cordycepin with more consistent quality and anti-proliferative/anti-migratory activity toward cancer cells.

\section{Acknowledgements}

This research was mainly supported by Agricultural Research Development Agency and partly supported by the National Research University Project of CHE and the Ratchadaphiseksomphot Endowment Fund (HR001B).

\section{References}

Ahn, Y. J., Park, S. J., Lee, S. G., Shin, S. C., \& Choi, D. H. (2000). Cordycepin: selective growth inhibitor derived from liquid culture of Cordyceps militaris against Clostridium spp. Journal of Agricultural and Food Chemistry, 48, 2744-2748. http://dx.doi.org/10.1021/j9990862n

Amir, Y., Haenni, A., \& You, A. (2007). Physical and biochemical differences in the composition of the seeds of Algerian leguminous crops. Journal of Food Composition and Analysis, 20, 466-471. http://dx.doi.org/10.1016/j.jfca.2007.01.001

Aramwit, P., Damrongsakkul, S., Kanokpanont, S., \& Srichana, T. (2010). Properties and antityrosinase activity of sericin from various extraction methods. Biotechnology and Applied Biochemistry, 55, 91-98. http://dx.doi.org/10.1042/BA20090186

Cavalieri, E. L., Li, K. M., Balu, N., Saeed, M., Devanesan, P., Higginbotham, S., .. Rogan, E. G. (2002). Catechol ortho-quinones: The electrophilic compounds that form depurinating DNA adducts and could initiate cancer and other diseases. Carcinogenesis, 23, 1071-1077. http://dx.doi.org/10.1093/carcin/23.6.1071 
Cunningham, K. G., Hutchinson, S. A., Manson, W., \& Spring, F. S. (1951). Cordycepin, a metabolic product from cultures of Cordyceps militaris(Linn.) link. Part I. Isolation and characterization. Journal of the Chemical Society, 2299-2300. http://dx.doi.org/10.1039/jr9510002299

Dai, X., Tan, Y., Cai, S., Xiong, X., Wang, L., Ye, Q., ... Cai, L. (2011). The role of CXCR7 on the adhesion, proliferation and angiogenesis of endothelial progenitor cells. Journal of Cellular and Molecular Medicine, 15, 1299-1309. http://dx.doi.org/10.1111/j.1582-4934.2011.01301.x

Das, S. K., Masuda, M., Hatashita, M., Sakurai, A., \& Sakakibara, M. (2010). Optimization of culture medium for cordycepin production using Cordyceps militaris mutant obtained by ion beam irradiation. Process Biochemistry, 45, 129-132. http://dx.doi.org/10.1016/j.procbio.2009.08.008

Edmondson, J. M., Armstrong, L. S., \& Martinez, A. O. (1988). A rapid and simple MTT based spectrophotometric assay for determining the drug sensitivity in monolayer cultures. Journal of Tissue Culture Methods, 11, 15-17. http://dx.doi.org/10.1007/BF01404408

Holliday, J., \& Cleaver, M. (2008). Medicinal value of the caterpillar fungi species of the genus cordyceps (Fr.) Link (Ascomycetes): a review. International Journal of Medicinal Mushrooms, 10, 219-234. http://dx.doi.org/10.1615/IntJMedMushr.v10.i3.30

Ikeda, R., Nishimura, M., Sun, Y., Wada, M., \& Nakashima, K. (2008). Simple HPLC-UV determination of nucleosides and its application to the authentication of Cordyceps and its allies. Biomedical Chromatography, 22, 630-636. http://dx.doi.org/10.1002/bmc.980

Jeong, J. W., Jin, C. Y., Kim, G. Y., Lee, J. D., Park, C., Kim, G. D., ... Choi, Y. H. (2010). Anti-inflammatory effects of cordycepin via suppression of inflammatory mediators in BV2 microglial cells. International Journal of Immunopharmacology, 10, 1580-1586.

Jeong, J. W., Jin, C. Y., Park, C., Han, M. H., Kim, G. Y., Moon, S. K., ... Choi, Y. H. (2012). Inhibition of migration and invasion of $\mathrm{LNCaP}$ human prostate carcinoma cells by cordycepin through inactivation of Akt. International Journal of Oncology, 40, 1697-1704.

Jeong, M. H., Seo, M. J., Park, J. U., Kang, B. W., Kim, K. S., Lee, J. Y., ... Jeong, Y. K. (2012). Effect of cordycepin purified from Cordyceps militaris on Th1 and Th2 cytokines in mouse splenocytes. Journal of Microbiology and Biotechnology, 22, 1161-1164. http://dx.doi.org/10.4014/jmb.1203.03039

Khan, M. A., Tania, M., Zhang, D. Z., \& Chen, H. C. (2010). Cordyceps mushroom: a potent anticancer $\begin{array}{lllll}\text { nutraceutical. The Open Nutraceuticals Journal, } & \text { 3, }\end{array}$ http://dx.doi.org/10.2174/1876396001003010179

Kim, H. G., Shrestha, B., Lim, S. Y., Yoon, D. H., Chang, W. C., Shin, D. J., ... Kim, T. W. (2006). Cordycepin inhibits lipopolysaccharide-induced inflammation by the suppression of NF-kappaB through Akt and p38 inhibition in RAW 264.7 macrophage cells. European Journal of Pharmacology, 545, 192-199. http://dx.doi.org/10.1016/j.ejphar.2006.06.047

Lee, E. J., Kim, W. J., \& Moon, S. K. (2010). Cordycepin suppresses TNF-alpha-induced invasion, migration and matrix metalloproteinase-9 expression in human bladder cancer cells. Phytotherapy Research, 24, 1755-1761. http://dx.doi.org/10.1002/ptr.3132

Lee, J. H., Hong, S. M., Yun, J. Y., Myoung, H., \& Kim, M. J. (2011). Anti-cancer effects of cordycepin on oral squamous cell carcinoma proliferation and apoptosis in vitro. Journal of Cancer Therapy, 2, 224-234. http://dx.doi.org/10.4236/jct.2011.22029

Lee, S. J., Kim, S. K., Choi, W. S., Kim, W. J., \& Moon, S. K. (2009). Cordycepin causes p21WAF1-mediated G2/M cell-cycle arrest by regulating c-Jun Nterminal kinase activation in human bladder cancer cells. Archives of Biochemistry and Biophysics, 490, 103-109. http://dx.doi.org/10.1016/j.abb.2009.09.001

Li, S. P., Su, Z. R., Dong, T. T., \& Tsim, K. W. (2002). The fruiting body and its caterpillar host of Cordyceps sinensis show close resemblance in main constituents and anti-oxidation activity. Phytomedicine, 9, 319-324. http://dx.doi.org/10.1078/0944-7113-00134

Ling, J. Y., Zhang, G. Y., Lin, J. Q., Cui, Z. J., \& Zhang, C. K. (2009). Supercritical fluid extraction of cordycepin and adenosine from Cordyceps kyushuensis and purification by high-speed counter-current chromatography. Separation and Purification Technology, 66, 625-629. http://dx.doi.org/10.1016/j.seppur.2008.12.022

Lynch, J. M., \& Barbano, D. M. (1999). Kjeldahl nitrogen analysis as a reference method for protein determination in dairy products. Journal of AOAC International, 82, 1389-1398. 
Mao, X. B., Eksriwong, T., Chauvatcharin, S., \& Zhong, J. J. (2005). Optimization of carbon source and carbon/nitrogen ratio for cordycepin production by submerged cultivation of medicinal mushroom Cordyceps militaris. Process Biochemistry, 40, 1667-1672. http://dx.doi.org/10.1016/j.procbio.2004.06.046

Masamoto, Y., Ando, H., Murata, Y., Shimoishi, Y., Tada, M., \& Takahata, K. (2003). Mushroom tyrosinase inhibitory activity of esculetin isolated from seeds of Euphorbia lathyris L. Bioscience, Biotechnology, and Biochemistry, 67, 631-634. http://dx.doi.org/10.1271/bbb.67.631

Masuda, M., Das, S. K., Fujihara, S., Hatashita, M., \& Sakurai, A. (2011). Production of cordycepin by a repeated batch culture of a Cordyceps militaris mutant obtained by proton beam irradiation. Journal of Bioscience and Bioengineering, 111, 55-60. http://dx.doi.org/10.1016/j.jbiosc.2010.08.018

Masuda, M., Urabe, E., Sakurai, A., \& Sakakibara, M. (2006). Production of cordycepin by surface culture using the medicinal mushroom Cordyceps militaris. Enzyme and Microbial Technology, 39, 641-646. http://dx.doi.org/10.1016/j.enzmictec.2005.11.010

Mosmann, T. (1983). Rapid colorimetric assay for cellular growth and survival: Application to proliferation and cytotoxicity assays. Journal of Immunological Methods, 65, 55-63. http://dx.doi.org/10.1016/0022-1759(83)90303-4

Ng, T. B., \& Wang, H. X. (2005). Pharmacological actions of Cordyceps, a prized folk medicine. Journal of Pharmacology and Pharmacotherapeutics, 57, 1509-1519. http://dx.doi.org/10.1211/jpp.57.12.0001

Ni, H., Zhou, X. H., Li, H. H., \& Huang, W. F. (2009). Column chromatographic extraction and preparation of cordycepin from Cordyceps militaris waster medium. Journal of Chromatography B, 877, $2135-2141$. http://dx.doi.org/10.1016/j.jchromb.2009.06.009

Nollet, L. M. L. (2004). Handbook of food analysis: Physical characterization and nutrient analysis. New York: Marcel-Dekker Inc.

Patel, K. J., \& Ingalhalli, R. S. (2013). Cordyceps militaris (L.: Fr.) link - an important medicinal mushroom. Journal of Pharmacognosy and Phytochemistry, 3, 315-319.

Paterson, R. R. M. (2008). Cordyceps - a traditional Chinese medicine and another fungal therapeutic biofactory? Phytochemistry, 69, 1469-1495. http://dx.doi.org/10.1016/j.phytochem.2008.01.027

Schurink, M., van Berkel, W. J., Wichers, H. J., \& Boeriu, C. G. (2007). Novel peptides with tyrosinase inhibitory activity. Peptides, 28, 485-495. http://dx.doi.org/10.1016/j.peptides.2006.11.023

Tee, E. S., Kuladevan, R., Ing, Y. S., Choo, K. S., \& Omar, Z. H. (1996). Laboratories procedures in nutrient analysis of foods. Kuala Lumpur, Malaysia: Division of Human Nutrition, Institute for Medical Research.

Wu, W. C., Hsiao, J. R., Lian, Y. Y., Lin, C. Y., \& Huang, B. M. (2007). The apoptotic effect of cordycepin on human OEC-M1 oral cancer cell line. Cancer Chemotherapy and Pharmacology, 60, $103-111$. http://dx.doi.org/10.1007/s00280-006-0354-y

Yoshikawa, N., Nakamura, K., Yamaguchi, Y., Kagota, S., Shinozuka, K., \& Kunitomo, M. (2004). Antitumour activity of cordycepin in mice. Clinical and Experimental Pharmacology and Physiology, 31, 51-53. http://dx.doi.org/10.1111/j.1440-1681.2004.04108.x

Yoshikawa, N., Yamada, S., Takeuchi, C., Kagota, S., Shinozuka, K., Kunitomo, M., \& Nakamura, K. (2008). Cordycepin (3'- deoxyadenosine) inhibits the growth of B16-BL6 mouse melanoma cells through the stimulation of adenosine A3 receptor followed by glycogen synthase kinase-3beta activation and cyclin D1 suppression. Naunyn-Schmiedeberg's Archives of Pharmacology, 377, 591-595. http://dx.doi.org/10.1007/s00210-007-0218-y

Zhang, P., Wang, J., Gao, W., Yuan, B. Z., Rogers, J., \& Reed, E. (2004). CHK2 kinase expression is down-regulated due to promoter methylation in non-small cell lung cancer. Molecular Cancer, 3, 14-23. http://dx.doi.org/10.1186/1476-4598-3-14

Zhu, J. S., Halpern, G. M., Jones, K. (1998). The scientific rediscovery of an ancient Chinese herbal medicine: Cordyceps sinensis: Part I. Journal of Alternative and Complementary Medicine, 4, 289-303. http://dx.doi.org/10.1089/acm.1998.4.3-289

Zhu, L., Liang, Y., Lao, D., Zhang, T., \& Ito, Y. (2011). Preparative separation of high-purity cordycepin from Cordyceps militaris(L.) Link by high-speed countercurrent chromatography. Journal of Liquid Chromatography \& Related Technologies, 37, 491-499. 


\section{Copyrights}

Copyright for this article is retained by the author(s), with first publication rights granted to the journal.

This is an open-access article distributed under the terms and conditions of the Creative Commons Attribution license (http://creativecommons.org/licenses/by/3.0/). 